\title{
The effect of ecological factors on a cardiovascular system of children
}

\author{
Sultan Tuleukhanov ${ }^{1}$, Zhanna Abdrassulova, ${ }^{1, *}$, Nurdana Salybekova ${ }^{2}$, Gulzhaina \\ Alpamyssova $^{3}$, and Arina Kenshilik ${ }^{1}$ \\ ${ }^{1}$ Al-Farabi Kazakh National University, al-Farabi Ave. 71, 050040 Almaty, Republic of Kazakhstan \\ ${ }^{2}$ Khoja Akhmet Yassawi International Kazakh-Turkish University, B.Sattarkhanov Ave, 29, 161200 \\ Turkestan, Republic of Kazakhstan \\ ${ }^{3}$ South Kazakhstan State Pedagogical Institute, A.Baitursynov Street 13, 160012 Shymkent, Republic \\ of Kazakhstan
}

\begin{abstract}
This study provides examination of cardiovascular system of children who live in Ust-Kamenogorsk, mainly in its environmentally polluted areas as industrial zones and Ulbinsk region. The work focused on studying the age and gender characteristics of the cardio vascular system in children living in environmentally unfavorable conditions of UstKamenogorsk. The study highlighted the role of contamination into the development of many diseases that affect cardiovascular system of children in various age categories. The features of cardiorespiratory system were evaluated by methods of pneumotachometry, variational pulsometry, electrocardiography, Holter daily monitoring of electrocardiography. There was detected a gradual increase in sympathetic regulation of heart rate in boys and humoral regulation in girls aged 9-12 years. It was shown that the resistance of children's organism to the harmful environmental effects depend on their constitutional features. The increased level of stress also affects the well-being of children, as caused by the unfavourable conditions. The method of daily ECG monitoring revealed an increase in the frequency of elevation ST segment, to a lesser extent its depression, so the incidence of bradycardia is more often than tachycardia.
\end{abstract}

\section{Introduction}

The city of Ust-Kamenogorsk was and remains among the most polluted cities in the world [1]. After a temporary pause (1993-1998) decline in production today the city's industry it is characterized by an increase in production volumes. More than 80 chemical compounds in the form of dust, gaseous and aerosol fractions, including the metals of the 1st class dangers have been found in atmosphere of Ust-Kamenogorsk. Long-term system analysis of atmospheric pollution composition and morbidity, conducted by the office of Public healthepidemiological surveillance, revealed a clear correlation of cause and the effect of the level of pollution on the health of the population [2]. For the first time age and sex characteristics of the cardiorespiratory system were studied based on a comprehensive survey of children 6-

\footnotetext{
*Corresponding author: Zhanna.Abdrassulova@kaznu.kz
} 
15 years old living in Ust-Kamenogorsk: age dynamics of functional conditions of bronchial patency in children and its features relative to the Central European standards; specifics of heart rate regulation in children of different ages and sex; the dynamics of daily ECG of children. There was revealed the dependence of functional state of the bronchopulmonary and cardiovascular system of children from the level of environmental pollution: in children living in more contaminated area, there were detected signs of reduction of functional reserves of the studied systems. The role of constitutional factor of children in the risk of diseases was determined: children who have the growth-weight ratio higher than the average value, revealed more reduction of functional reserves of the bronchopulmonary system, and children with the coefficient lower than the average had reduction of the cardiovascular system.

Diseases of the circulatory system has increased from 154,1 to 163,4. According to expert data the territory of Ust-Kamenogorsk was divided into districts by degree of danger to public health. The most polluted and dangerous is the Ulba district, where the main industrial zone (OJSC Kazzinc, Ulba metallurgical factory and etc.) [3-5].

There are only a few works that have studied anthropometric data, level of physical development of children living in East Kazakhstan [6-8].

A number of researchers have identified fairly clear changes of regulatory functions of the cardiovascular system under the influence of various factors that can be used to judge adaptation capabilities of the organism [9-11].

In this regard, the purpose of our investigation was to study physiological features of the cardiorespiratory system of boys and girls of various ages living in environmentally unfavorable conditions of Ust-Kamenogorsk.

\section{Materials and methods}

The choice of methodical techniques and the volume of research were determined by the purpose and objectives of this work. In order to solve the tasks 42 children without the established pathology were examined: 21 boys and 21 girls at the ages $6-15$ years, who live in Ust-Kamenogorsk. The examined children were conditionally divided into three age groups of 6-8 years, 9-12 years, 13-15 years, respectively (according to age periodization). The group №1 included children who live in less hazardous area for population, such as the district of the silk factory; a group №2 is represented by children who live in extremely hazardous area for population: Ulba district [4]. The studies were conducted in the department of functional diagnostics of the health unit-2 in Ust-Kamenogorsk. The temperature in the room was $18-20^{\circ} \mathrm{C}$. The examination of children was conducted in a spring-summer period. The conducted research consisted of reserve opportunities study of children's cardiorespiratory system depending on the age and gender. Complex examination of children has begun with the registration of information about the state of health, overall well-being, and age. The anthropometric data were measured with the help of stadiometer and medical scales. The arterial pressure was measured auscultatory, according to Korotkov's method with the help of phonendoscope and tonometer (systolic arterial pressure - Aps, diastolic aryerial pressure - Apd).

Functional features of cardiorespiratory system were evaluated by methods of pneumotachometry, variational pulsometry, electrocardiography, Holter daily monitoring of electrocardiography.

The study of a cardiovascular system was conducted by the method of electrocardiography with the help of "Marguette-Hellige" electrocardiograph apparatus.

Daily monitoring of ECG was conducted with the help of Holter Works-plus "Quinton" (USA) device. The research was held from 8 am until 8 am of the next day.

Reaction of cardiovascular system to the leaning of torso - Belgian test. 
Determination of the adaptive potential of circulatory system, health coefficient (HC) by R.M.Bayevsky's formula.

The anxiety personality rating scale (AP) was determined by the method of C. Spielberger and Y.L.Khanin [12].

The statistical processing was done with the help of a program Basic Statistics, and the reliability of differences were identified according to Student's criteria (Urbach B.Y., 1978). Quantitative characteristics were given on the basis of correlational analysis of experimental material.

\section{Results and discussion}

Results of anthropometric measurements presented in table 1, they correspond to age-related patterns of growth and development. It can be noted that boys and girls of the first and second age groups have the same length and weight indicators. At the age of 13-15 years, the length and body weight (p:0,05) higher for boys than girls, which means that a greater the rate of morphofunctional growth of boys in puberty. The difference between the length and weight of the body between the second and third the age range is $\Delta \mathrm{R}=25.15 \mathrm{~cm}, \Delta \mathrm{m}=20.43 \mathrm{~kg}$ for boys and $\Delta \mathrm{R}=14.75 \mathrm{~cm}, \Delta \mathrm{m}=8.73 \mathrm{~kg}$ for girls. Comparative information between the first and second age group: $\Delta \mathrm{R}=20.85 \mathrm{~cm}, \Delta \mathrm{m}=11.57 \mathrm{~kg}$ allow us to conclude that girls puberty jump is observed in the age group of 9-12 years, apparently there are two jumps in boys, aged 912 and 13-15. This is consistent with a lot of literary data about earlier maturation of girls compared to boys. At the same time, it was revealed that the growth spurt includes two phases [13-15]. The growth/mass ratio $(\mathrm{P} / \mathrm{m})$ of the body tends to decrease with age, and boys in the age group of 13-15 years in the greater degree than in girls ( $\mathrm{p} " 0.05)$, which indicates a more intense increase in height than increase in body weight according to age morpho-functional regularities.

Table 1. Anthropometric data of boys and girls of three age groups.

\begin{tabular}{l|c|c|c|c|c|c}
\hline & \multicolumn{3}{|c|}{ Boys } & \multicolumn{3}{c}{ Girls } \\
\cline { 2 - 8 } & $\begin{array}{c}\text { 6-8 y.o., } \\
\mathrm{n}=18\end{array}$ & $\begin{array}{c}9-12 \text { y.o., } \\
\mathrm{n}=18\end{array}$ & $\begin{array}{c}13-15 \text { y.o., } \\
\mathrm{n}=19\end{array}$ & $\begin{array}{c}\text { 6-8 y.o., } \\
\mathrm{n}=21\end{array}$ & $\begin{array}{c}9-12 \text { y.o., } \\
\mathrm{n}=23\end{array}$ & $\begin{array}{c}13-15 \text { y.o., } \\
\mathrm{n}=20\end{array}$ \\
\hline Body length, cm & $122,71 \pm 2,79$ & $141,42 \pm 4,66$ & $166,57 \pm 4,63$ & $123 \pm 2,66$ & $143,85 \pm 3,73$ & $158,57 \pm 3,82$ \\
\hline Weight, kg & $26,14 \pm 1,84$ & $36,28 \pm 1,88$ & $56,71 \pm 1,70^{*}$ & $25,28 \pm 1,44$ & $36,85 \pm 2,25$ & $45,57 \pm 2,65^{*}$ \\
\hline P/m & $4,81 \pm 0,34$ & $3,92 \pm 0,15$ & $2,97 \pm 0,04^{*}$ & $4,97 \pm 0,31$ & $3,95 \pm 0,19$ & $3,54 \pm 0,19^{*}$ \\
\hline
\end{tabular}

Note: significant sex differences within the same age $\left(\mathrm{p}<0,05^{*}\right)$

It is necessary to pay attention to the fact that this is expressed in girls more than boys, indicating greater sensitivity girls'. This is also confirmed by the above data on volume: lung function.

Age and sex characteristics of the cardiovascular system. Blood pressure and heart rate Indicators abbreviations at rest. The reaction of the HRF and the maximum delay of breathing on bending the torso (Belgian test). Indicators of the health coefficient (according to R. M. Baevsky) as a characteristic of the adaptive potential of the circulatory system.

Heart rate and blood pressure values in three age groups of boys and girls correspond to the norm; there are no significant differences between pears detected. Only in the group of 9-12 years the ADF index in boys significantly higher than in girls (Table 2).

Sexual differences were found in the response of the heart rate to the maximum breathholding. In boys of the first and third age groups the PR1 index is significantly higher than that of girls. You should pay attention to the duration of maximum breath retention. You can see that in the group of boys $6-8$ years of age, the duration of $\mathrm{MBH}$ is the lowest $(18,14 \pm 2,94$ 
s), and in the group boys 13-15 years of age the highest (65.71 $\pm 7.27 \mathrm{~s}$ ), a higher value of PR1 (but still normal to 1,2 ) and the older age group can be explained a sufficiently long delay time (almost twice as long as the girls of the appropriate age and three times as much as the younger group boys').

Table 2. Indicators of the cardiovascular system of boys and girls of three age groups.

\begin{tabular}{l|c|c|c|c|c|c}
\hline & \multicolumn{3}{|c|}{ Boys } & \multicolumn{3}{c}{ Girls } \\
\cline { 2 - 7 } & $\begin{array}{c}\text { 6-8 y.o., } \\
\mathrm{n}=18\end{array}$ & $\begin{array}{c}9-12 \text { y.o., } \\
\mathrm{n}=18\end{array}$ & $\begin{array}{c}13-15 \text { y.o., } \\
\mathrm{n}=19\end{array}$ & $\begin{array}{c}6-8 \text { y.o., } \\
\mathrm{n}=21\end{array}$ & $\begin{array}{c}9-12 \text { y.o., } \\
\mathrm{n}=23\end{array}$ & $\begin{array}{c}13-15 \text { y.o., } \\
\mathrm{n}=20\end{array}$ \\
\hline HRF & $85,14 \pm 4,71$ & $89,71 \pm 4,39$ & $86,85 \pm 4,40$ & $92,71 \pm 3,71$ & $82,14 \pm 5,62$ & $86,28 \pm 3,76$ \\
\hline MBH & $18,14 \pm 2,94$ & $26,28 \pm 5,28$ & $65,71 \pm 7,27$ & $26,57 \pm 3,43$ & $45 \pm 8,01$ & $37,14 \pm 7,78^{*}$ \\
\hline ADs & $71,42 \pm 1,42$ & $77,14 \pm 2,85^{*}$ & $77,14 \pm 2,85$ & $70 \pm 2,18$ & $67,14 \pm 1,84^{*}$ & $74,28 \pm 2,02$ \\
\hline ADd & $110 \pm 0,0$ & $112,85 \pm 1,84$ & $112.85 \pm 2,96$ & $107,14 \pm 1,84$ & $110,71 \pm 2,29$ & $114,28 \pm 2,02$ \\
\hline RR1 & $1,21 \pm 0,07^{*}$ & $1,15 \pm 0,04$ & $1,18 \pm 0,09$ & $1,07 \pm 0,02^{*}$ & $1,21 \pm 0,06$ & $1,04 \pm 0,02^{* *}$ \\
\hline RR2 & $0,10 \pm 0,01$ & $0,13 \pm 0,02^{*}$ & $0,08 \pm 0,01$ & $0,14 \pm 0,01$ & $0,05 \pm 0,01$ & $0,09 \pm 0,01$ \\
\hline HC & $1,72 \pm 0,05$ & $1,78 \pm 0,15^{*}$ & $1,84 \pm 0,11$ & $1,76 \pm 0,04$ & $1,55 \pm 0,04^{*}$ & $1,72 \pm 0,07$ \\
\hline
\end{tabular}

Note: significant sex differences within the same age $\left(\mathrm{p}<0,05^{*}\right)$ significant sex differences within the same age $(\mathrm{p}<0,01 * *)$

Whereas the combination of the minimum value of $\mathrm{MBH}$ and a high index of PR1 (above 1.2) in boys of the younger group is likely indicates a decrease in the cardiorespiratory reserve. At the same time, indicators of the cardiovascular system's response to the torso tilts showed no significant differences. Displays PR2 in all groups correspond to the norm and have similar values almost in children. The lowest values of PR2 in girls 9-12 years old differ significantly from the corresponding values in boys.

Values of the health coefficient that characterize the adaptive potential of the circulatory system [12] have a level of «satisfactory» adaptation (close to 2) in all children. You can note, that this indicator is relatively better in the group of girls 9-12 years old (lowest $p$ value: $0.05)$,

Thus, according to the above data, we can say that the most optimal indicators that characterize the heart rate-vascular system, observed in girls 9-12 years. It is possible that girls in puberty there is a large optimization of the studied indicators. However, the PR1 index of this group of girls indicates a decrease in the cardiorespiratory reserve (more than 1.2). Given that the duration of maximum breath retention is the second the age group is longer (45 min, which is defined as "satisfactory" cardiorespiratory reserve). Than in others age groups, we believe that after all, for a more correct interpretation of the indicator PR1 should be performed breath holding with the specified time, or to calculate the PR based on delay time. For example PR1 in girls of the first and third groups indicates optimal cardiorespiratory reserve (below 1.2) at the same time. The duration of maximum breath retention indicates an "unsatisfactory" level of cardiorespiratory reserves.

The results of ECG studies of boys and girls of three age groups are presented in table 3. In the process of growth and development of the child absolute and relative dimensions of the heart, its location in the chest the cell is constantly changing, which affects the features of a child's ECG. The development of the child is purely individual. We tried to determine the average age of ECG standards. The increased heart rate on ECG the tendency to decrease with age only in girls, more in the age group is 9-12 years old.

Table 3. Indicators of ECG of boys and girls of three age groups.

\begin{tabular}{c|c|c|c|c|c|c}
\hline & \multicolumn{3}{|c|}{ Boys } & \multicolumn{3}{c}{ Girls } \\
\cline { 2 - 7 } & $\begin{array}{c}\text { 6-8 y.o., } \\
\mathrm{n}=18\end{array}$ & $\begin{array}{c}9-12 \text { y.o., } \\
\mathrm{n}=18\end{array}$ & $\begin{array}{c}13-15 \text { y.o., } \\
\mathrm{n}=19\end{array}$ & $\begin{array}{c}\text { 6-8 y.o., } \\
\mathrm{n}=21\end{array}$ & $\begin{array}{c}9-12 \text { y.o., } \\
\mathrm{n}=23\end{array}$ & $\begin{array}{c}13-15 \text { y.o., } \\
\mathrm{n}=20\end{array}$ \\
\hline Vent.Rate & $85,14 \pm 4,71$ & $89,71 \pm 4,39$ & $86,85 \pm 4,40$ & $92,71 \pm 3,71$ & $82,14 \pm 5,62$ & $86,28 \pm 3,76$ \\
\hline
\end{tabular}




\begin{tabular}{c|c|c|c|c|c|c}
\hline PR interval & $122,28 \pm 4,17$ & $122,85 \pm 3,56$ & $145,14 \pm 8,71$ & $122,85 \pm 6,57$ & $135,42 \pm 6,49$ & $133,71 \pm 9,98$ \\
\hline QRS duration & $80,00 \pm 2,13$ & $81,71 \pm 3,00$ & $95,42 \pm 3,74 *$ & $76,00 \pm 3,80$ & $77,71 \pm 3,47$ & $80,00 \pm 1,95^{*}$ \\
\hline QT & $358,85 \pm 8,17 *$ & $345,71 \pm 5,91$ & $357,71 \pm 7,02$ & $334,85 \pm 5,83^{*}$ & $357,14 \pm 9,22$ & $353,14 \pm 5,36$ \\
\hline QTc & $414,14 \pm 4,78$ & $418,28 \pm 5,19$ & $431,85 \pm 5,72$ & $411,00 \pm 6,62$ & $410,00 \pm 7,22$ & $418,57 \pm 7,90$ \\
\hline P-axes & $42,14 \pm 7,70$ & $42,28 \pm 5,48$ & $52,00 \pm 7,29$ & $40,42 \pm 8,83$ & $41,14 \pm 6,04$ & $54,14 \pm 6,56$ \\
\hline R-axes & $67,14 \pm 8,95$ & $59,14 \pm 9,79$ & $74,42 \pm 11,79$ & $68,14 \pm 9,57$ & $64.28 \pm 9,98$ & $76,57 \pm 3,69$ \\
\hline T-axes & $49,00 \pm 2,99$ & $45,28 \pm 3,70$ & $42,14 \pm 3,94$ & $31,42 \pm 6,53^{*}$ & $43,00 \pm 4,93$ & $44,42 \pm 5,93$ \\
\hline
\end{tabular}

Note: significant sex differences within the same age $\left(\mathrm{p}<0,05^{*}\right)$

The PR interval reflects the process of the spread of excitation from the atria to the ventricles. With age, this indicator increases, in boys there is an increase in duration at the age of 13-15 years, in girls aged 9-12 years, which is probably due to earlier maturation. In absolute terms, the value of this interval for boys 13-15 years old is higher than for girls of the corresponding age.

The QRS interval, indicating the time of propagation of excitation in the myocardium of the ventricles, increases linearly with age, which is more pronounced in boys $(p<0.05)$. In girls, the values of this indicator are lower than in boys, especially in the third age group ( $p$ $<0.05)$.

The values of the QT values of the intervals characterizing the duration of the ventricular electrical systole in all children are within the normal range (normal up to $480 \mathrm{~ms}$ ). In boys, the value of this indicator in the second age group is lower than in the first age group. In the third age group, the same values as in the first. Girls have the highest values of this indicator at the age of 9-12 years, which coincide in magnitude with those of boys of 13-15 years old, and the lowest indicators at the age of 6-8 years are significantly lower than for boys of the corresponding age.

How much different is the indicator of QTc. In boys, a gradual increase in its activity is observed, more pronounced at the age of 13-14 years. In girls, significant changes are not observed, there is only a slight tendency to increase with age.

It was somewhat difficult to generalize data on deviations of the electrical axis of the heart due to their individual diversity in groups. In the literature there is evidence of "horizontal" position of the heart with age [15-16], however, according to our data, we cannot draw such conclusions.

As can be seen from the presented results, the duration of the intervals tends to increase with age, which is consistent with published data, although the question of age-related standards for pediatric ECG has not yet been completely resolved. The literature provides different standards. Some of our figures also do not coincide with those available in the literature. For example, the amplitude decreases with age, in girls it increases.

Thus, an ECG study revealed age and some sexual characteristics: a decrease in heart rate; increase in the duration of teeth, intervals and segments of the ECG; an increase in the amplitude of the $\mathrm{P}$ and $\mathrm{R}$ teeth in all children; a decrease in the amplitude of the $\mathrm{E}$ wave in boys and an increase in it in girls.

Age and gender characteristics of variational pulsometry indicators. Using the method of variational pulsometry for processing the obtained data allowed us to identify age and gender characteristics of the regulation of heart rhythm, as well as the degree of tension of regulatory systems as a criterion of adaptive potential in environmental conditions (Table 4). The indicator Mo, indicating the most probable level of functioning of the circulatory system, is significantly higher in boys at the age of $6-8$ than in girls $(\mathrm{p}<0.05)$, slightly lower in boys of 9-12 years old than in girls, and almost the same - at the age of 13-15 years. These data correspond to the heart rate indicators given above. The highest Mo $(0.67 \pm 0.03)$ in girls of the 9-12 year old group corresponds to the lowest heart rate $(82.14 \pm 5.62$ beats $/ \mathrm{min})$. The lowest Mo $(0.61 \pm 0.01)$ in girls of the group of 6-8 years old is consistent with the highest heart rate $(92.71 \pm 3.71 \mathrm{bpm})$. It is also known that Mo characterizes the humoral regulation 
channel. And its highest value in girls aged 9-12 years suggests that in girls at the beginning of the puberty, humoral regulation becomes significantly more significant than sympathetic.

AMo values, reflecting the effect of centralization of heart rhythm control, increase with age in all children, except for the group of girls aged 9-12 who have the lowest values of this indicator $(44.28 \pm 4.80)$. The data indicate an increase in the influence of the sympathetic part of the autonomic nervous system on the regulation of cardiac activity with age, which, of course, is associated with puberty. An exception was a decrease in the sympathetic effect on heart regulation in girls aged 9-12 years.

The $\Delta \mathrm{X}$ indicator, indicating the degree of variability of the values of cardio intervals, revealed a clear tendency to decrease in all children, more pronounced in boys (significant difference between the younger and older age groups, $\mathrm{p}<0.05$ ).

Table 4. Indicators of variational pulsometry in boys and girls of three age groups.

\begin{tabular}{l|c|c|c|c|c|c}
\hline & \multicolumn{3}{|c|}{ Boys } & \multicolumn{3}{c}{ Girls } \\
\cline { 2 - 7 } & $\begin{array}{c}6-8 \text { y.o., } \\
\mathrm{n}=18\end{array}$ & $\begin{array}{c}9-12 \text { y.o., } \\
\mathrm{n}=18\end{array}$ & $\begin{array}{c}13-15 \text { y.o., } \\
\mathrm{n}=19\end{array}$ & $\begin{array}{c}6-8 \text { y.o., } \\
\mathrm{n}=21\end{array}$ & $\begin{array}{c}9-12 \text { y.o., } \\
\mathrm{n}=23\end{array}$ & $\begin{array}{c}13-15 \text { y.o., } \\
\mathrm{n}=20\end{array}$ \\
\hline Mo & $0,66 \pm 0,01^{*}$ & $0,65 \pm 0,03$ & $0,65 \pm 0,03$ & $0,61 \pm 0,01^{*}$ & $0,67 \pm 0,03$ & $0,66 \pm 0,03$ \\
\hline AMo,\% & $49,28 \pm 5,91^{\circ}$ & $56,42 \pm 4,84$ & $65 \pm 6,90^{\circ}$ & $58,57 \pm 7,04$ & $44,28 \pm 4,80$ & $52,85 \pm 4,73$ \\
\hline$\Delta$ X,c & $0,18 \pm 0,02^{\circ}$ & $0,16 \pm 0,01$ & $0,11 \pm 0,01^{\circ}$ & $0,16 \pm 0,02$ & $0,13 \pm 0,02$ & $0,13 \pm 0,01$ \\
\hline VI, cond.unit & $259,14 \pm 69,07^{\circ}$ & $269,71 \pm 43,79$ & $494,42 \pm 77,67$ & $367,28 \pm 82,6$ & $285,85 \pm 61$, & $342,85 \pm 48$, \\
& & & 4 & 90 & 59 \\
\hline VEI & $325,85 \pm 78,58^{\circ}$ & $341,42 \pm 46,36$ & $638,85 \pm 94,9$ & $444,28 \pm 97,5$ & $364,4 \pm 63,3$ & $439,42 \pm 50$, \\
& & & & 7 & 3 & $28^{*}$ \\
\hline AIRP & $76,85 \pm 10.93^{\circ}$ & $88 \pm 9,93$ & $100 \pm 10.91^{*}$ & $96,57 \pm 12,47$ & $61,71 \pm 10,2$ & $82,57 \pm 10,1$ \\
& & & & & 4 & $6^{*}$ \\
\hline
\end{tabular}

Note: significant sex differences within the same age $\left(\mathrm{p}<0,05^{*}\right)$ significant differences compared to two ages $\left(\mathrm{p}<0,05^{\circ}\right)$

8 years of age have lower IN than girls. Boys 13-15 years old are slightly higher than girls. It should be noted that according to their values, the ID in all children is above 200, which is defined as an "unsatisfactory" degree of adaptation with high sympathicotonic regulation.

IVR as an indicator of the ratio between the activity of the sympathetic and parasympathetic parts of the autonomic nervous system has the same trends as the stress index: it increases with age in boys, in girls 9-12 years old lower than in other groups.

In our studies, there was a decrease in ST after the onset of rhythm disturbance, which indicated a certain rhythm disturbance, possibly leading to functional oxygen deficiency.

Thus, the obtained data revealed the following age and gender characteristics:

Smaller heart rates during the day in children of the older age group, higher heart rates in children of the younger age group.

The CI (circadian index) values tend to increase with age and are normal in all children.

The values of N-N intervals, respectively, have the opposite tendency.

The boys revealed a large difference between the maximum and daily value of the N-N interval and the minimum night value.

The duration of bradycardia is maximum in the third in children of the second age group and minimum in the first in boys and in the third in girls.

The duration of tachycardia is maximum in boys in the second age group and in girls in the third age group.

The results of the study of indicators of $\mathrm{MBH}, \mathrm{APd}$, APs did not reveal significant differences between the groups. However, the more interval PR1 index in boys living in the more polluted region is significantly lower than in group 1 boys $(\mathrm{p}<0.05)$. It is known that 
the value of PR1 greater than 1.2 indicates a decrease in the cardiorespiratory reserve. Since the PR1 indicator is an estimate of the HRF response to maximum breath retention, we can say that the HRF is more reactive in boys living in district 1 compared to boys in district 2, contrary to the expected result. As we have already said, the growth and weight indicators of district 2 differ significantly from the corresponding indicators for boys in district 1 . At the same time, the indicator of the cardiovascular system response to physical activity (PR2) between the two groups has no significant differences and is estimated as "excellent heart condition". If you look at the HC indicators, they also do not differ significantly and relate to the "satisfactory" degree of adaptation of the circulatory system. There were no differences in these indicators for girls.

Comparative resting ECG scores for children living in district 1 and 2. Comparative results of ECG studies of children living in the first and second districts are provided in table 5. The HRF of girls living in a more polluted area is higher than that of girls in district 1 . No differences were found in boys.

Table 5. Indicators of the cardiovascular system of boys and girls living in the area (1) and (2).

\begin{tabular}{l|c|c|c|c}
\hline & Boys 1 & Boys 2 & Girls 1 & Girls 2 \\
\hline HRF & $87,77 \pm 3,43$ & $85,33 \pm 3,64$ & $82,77 \pm 3,83^{*}$ & $90,88 \pm 3,42^{*}$ \\
\hline MBH & $38,33 \pm 7,12$ & $40,55 \pm 10,56$ & $30,55 \pm 3,48$ & $36,22 \pm 6,26$ \\
\hline ADd & $11,11 \pm 1,11$ & $112,22 \pm 1,46$ & $112,22 \pm 1,46$ & $109,44 \pm 2,69$ \\
\hline ADs & $74,44 \pm 2,42$ & $74,44 \pm 2,42$ & $72,22 \pm 1,46$ & $68,88 \pm 2,60$ \\
\hline RR 1 & $1,22 \pm 0,05^{*}$ & $0,08 \pm 0,01^{*}$ & $1,10 \pm 0,034$ & $1,10 \pm 0,04$ \\
\hline RR 2 & $0,11 \pm 0,01$ & $0,08 \pm 0,01$ & $0,08 \pm 0,01$ & $0,09 \pm 0,02$ \\
\hline HC & $1,79 \pm 0,12$ & $1,72 \pm 0,06$ & $1,66 \pm 0,04$ & $1,68 \pm 0,07$ \\
\hline Note: significant differences within the same sex $(\mathrm{p}<0.05 *)$ \\
\hline
\end{tabular}

Thus, a comparison of ECG indicators in children of two different levels of contamination of areas revealed some difference in boys, which may have indicated some decrease in the regulatory properties of the sinus node. All ECG values were within the normal range.

Indicators of variational heart rate monitoring in children in two districts. It is interesting to note that when comparing indicators for boys and girls of the two groups, the opposite trends are observed. Indicators of IV, IVB in boys of group 2 are higher than in boys of group $1(\mathrm{p}<0.05)$. Girls who live in a more disadvantaged region have higher IV $(\mathrm{p}<0.05)$ and IVB scores than girls in group 1.

Analysis of variational heart rate monitoring indicators revealed a significantly high index of the voltage of the body's regulatory systems in groups of girls and boys above 200 units ( in girls 299 \pm 21.40 ; in boys $-383.11 \pm 63.85$ units, $\mathrm{p}<0.05$ ), living in a more polluted area of the city. It should be noted that in children living in district 1, indicators of IN, which have lower values relative to district 2 , are still quite high and indicate poor adaptation of all children (IV above 200 units).

The data obtained indicate that all the children surveyed have a predominant sympathicotonic type of regulation (IN more than 120 units) and all children have an unsatisfactory adaptation of the body to environmental conditions, and to a greater extent children living in a more polluted area.

Indicators of daily ECG monitoring by Holter. The analysis of daily HRF rate monitoring indicators presented in figures 3 and 4 revealed some differences in the two groups: in group 2 boys, the HRF is significantly higher between 12 AM and 2 PM than in group 1 boys; in group 2 girls, the HRF is slightly higher in the afternoon, and significantly higher between 5 and 6 PM $(\mathrm{p}<0.05)$.

The CI analysis showed that the ratio of day and night HRF levels is within the normal range and is defined as normal circadian heart rate profile, although in group 2 boys this 
indicator is close to the enhanced circadian rhythm profile, which is a sign of an increased tendency to paroxysmal rhythm disorders (Table 6).

Table 6. Average QI values for boys and girls living in the area (1) and (2).

\begin{tabular}{l|l|l|l|l}
\hline Time, h & Boys 1 & Boys 2 & Girls 1 & Girls 2 \\
\hline $07.00-14.00$ & $93,78 \pm 1,73$ & $98,98 \pm 2,08$ & $100,89 \pm 1,99$ & $101,23 \pm 1,76$ \\
\hline $15.00-22.00$ & $92,43 \pm 1,43$ & $93,69 \pm 1,57$ & $96,62 \pm 1,47$ & $98,89 \pm 1,27$ \\
\hline $23.00-06.00$ & $71,33 \pm 0,91^{*}$ & $67,97 \pm 1,08^{*}$ & $74,62 \pm 1,13^{* *}$ & $79,31 \pm 1,12^{* *}$ \\
\hline Daily average & $85,34 \pm 2,51$ & $86,35 \pm 3,20$ & $90,26 \pm 2,70$ & $94,39 \pm 2,37$ \\
\hline QI & $1,31 \pm 0,02$ & $1,46 \pm 0,08$ & $1,35 \pm 0,03$ & $1,28 \pm 0,04$ \\
\hline $\begin{array}{l}\left.\text { Note: significant differences within the same sex (p }<0.05^{*}\right) \\
\text { significant differences within the same sex (p<0.01 **) }\end{array}$ \\
\hline
\end{tabular}

The daily analysis of N-N intervals also revealed some significant differences: shorter interval duration in girls living in a more polluted area, after 2 PM to 3 AM $(p<0.05)$. This indicates an unfavorable reduction in the recovery period, leading to a strain of cardiac activity. In boys, this phenomenon is observed only from 12 AM to 4 PM, after 9 PM, the opposite trend was revealed: in boys living in a more polluted area, the duration of N-N intervals is higher.

\section{Conclusion}

As a result of complex ecological and physiological studies age, gender, regional and constitutional factors were identified features of the cardiorespiratory system of children living in Ust-Kamenogorsk:

1. Functional changes in the cardiovascular system with age characterized by a reduction in heart rate, lengthening cardiac cycle, stabilization of the circadian index. Daily ECG monitoring revealed an increase in the frequency of elevation ST segment, to a lesser extent its depression. Incidence of bradycardia is more often than tachycardia.

2 . The study of heart rate variability revealed differences in mechanisms of adaptation in boys and girls: gradual increase in sympathetic regulation of heart rate in boys and humoral regulation in girls aged 9-12 years. High values of the stress index in all children indicate that excessive the tension of regulatory systems correspond to "poor adaptation".

3. It is established that environmental factors of Ust-Kamenogorsk affect the state of the cardiorespiratory system of children. The nature and extent of this impact depends on the level of contamination place of residence.

4. It is shown that the children's body's resistance to the external environment depends on the constitutional features: children with growth and weight coefficient is higher than the average value are characterized by a decrease functional reserves of the bronchopulmonary system, and children with the coefficient lower than average, on the contrary, are characterized by decrease in the cardiovascular system.

\section{References}

1. Ministry of Environmental Protection in Parliament. Report Document: Ecology and Sustainable Development (2003)

2. V.N. Goldobin, R.B. Shin, R.A. Muzafarov, T.I. Muzafarova, VKGU, 180-187 (2002) 
3. L.G. Savelyeva, Physiological justification of the problem of adaptation of a growing organism in various regions of East Kazakhstan, 19 (1997)

4. V.L. Kozhar, Map of the state of habitats and health of the population of the East Kazakhstan region (1991)

5. G.A. Sadykova, A.M. Kustubaeva, Zh.A. Baydeldinova etc., Bulletin of the KazNU. Series of environmental, 2 (9), 74-79 (2001)

6. L.G. Savelyeva, N.A. Agadjanyan, VKGK, 90-103 (2002)

7. N.A. Agadjanyan, A.E. Severin, The reserves of the respiratory system: Interregional thematic collection of scientific papers, 112 (1999)

8. E.M. Kazin, H.G. Blinova, T.V. Dushenina, A.R. Galeyev, Human physiology, 1, 7076 (2003)

9. E.G. Potyagailo, V.M. Pokrovsky, Human physiology, 29(1), 59-63 (2003)

10. S.A. Kotelnikov, A.D. Nozdrachev, M.M. Odinak, E.B. Shustov, I.J. Kovalenko, V.J. Davydenko, Human physiology, 28(1), 130-143 (2002)

11. A. Dabrowski, B. Dabrowski, R. Piotrovich, Daily monitoring of ECG, 208 (2000)

12. Ch. Spielberg, J.L. Hanin, Workbook for practical training in valeology, 214-215 (1999)

13. J.V. Sereda, Electrocardiography in Pediatrics. Basic diagnostic algorithms, 92 (2004)

14. N.I. Vinogradova, J.R. Kovalev, Electrocardiography in Pediatrics, 25 (1979)

15. Z.B. Sabyrbek, S.T. Tuleukhanov, O.M. Alekseeva, Y.A. Kim, Modern Problems in Biochemical Physics: New Horizons, 281-292 (2012)

16. E.A. Kyrbassova, G.U. Baitasheva et al. International Journal of Pharmaceutical Research, 10(4), 689-697 (2018) 